\title{
Endoscopic ultrasound-guided radiofrequency ablation of pancreatic neuroendocrine tumors: a case series
}

\section{(ㄷ)(잉}

\section{Authors}

Germana de Nucci ${ }^{1}$, Nicola Imperatore ${ }^{2,3}$, Enzo Domenico Mandelli ${ }^{1}$, Franca di Nuovo ${ }^{4}$, Corrado d'Urbano ${ }^{5}$, Gianpiero Manes $^{1}$

Institutions

1 Gastroenterology and Endoscopy Unit, ASST Rhodense, Garbagnate Milanese, Milan, Italy

2 Gastroenterology, Department of Clinical Medicine and Surgery, School of Medicine Federico II of Naples, Naples, Italy

3 Gastroenterology and Endoscopy Unit, AORN A Cardarelli, Naples, Italy

4 Pathology Unit, ASST Rhodense, Garbagnate Milanese, Milan, Italy

5 Surgery Unit, ASST Rhodense, Garbagnate Milanese, Milan, Italy

submitted 16.4.2020

accepted after revision 18.8 .2020

\author{
Bibliography \\ Endoscopy International Open 2020; 08: E1754-E1758 \\ DOI 10.1055/a-1261-9359 \\ ISSN 2364-3722 \\ (C) 2020. The Author(s). \\ This is an open access article published by Thieme under the terms of the Creative \\ Commons Attribution-NonDerivative-NonCommercial License, permitting copying \\ and reproduction so long as the original work is given appropriate credit. Contents \\ may not be used for commecial purposes, or adapted, remixed, transformed or \\ built upon. (https://creativecommons.org/licenses/by-nc-nd/4.0/) \\ Corresponding author \\ Germana de Nucci, MD, Gastroenterology and Digestive \\ Endoscopy Unit , ASST Rhodense, Viale Forlanini 98, 0024, \\ Garbagnate Milanese, Milan, Italy \\ Fax: +3902994302905. \\ germanadenucci1@gmail.com
}

\section{ABSTRACT}

Background and study aims Surgery is the considered the therapeutic cornerstone for pancreatic neuroendocrine tumors (P-NETs), although burdened by high risk of significant adverse events. Recently, endoscopic ultrasound-guided radiofrequency ablation (EUS-RFA) has been described for P-NETs. We aimed to evaluate the effectiveness and safety of EUS-RFA for treatment of P-NETs.

Patients and methods We prospectively included all consecutive patients with P-NET $\leq 20 \mathrm{~mm}$ who were treated with EUS-RFA and were followed-up for at least 12 months. Results Ten patients ( 5 males, mean age 78.6 years, mean body mass index 28.2) with 11 P-NETs (mean size $14.5 \mathrm{~mm}$; range $9-20 \mathrm{~mm}$ ) localized in the pancreatic head (3 lesions), pancreatic body (5 lesions), and tail (3 lesions) underwent complete EUS ablation with one session of RFA. Complete ablation of P-NET was reached using a single-session RFA with a mean of 2.3 treatment applications per session. At both 6 -and 12-months computed tomography scans, all the patients had complete disappearance of lesions with radiological normalization. Regarding safety, only two cases of mild abdominal pain were recorded in two subjects with pancreatic head lesion, which were effectively treated with analgesics. The mean duration of hospital stay was 4 days (range $3-7$ days).

Conclusions EUS-RFA is effective and safe in treating PNETs. It may be considered an effective therapeutic option in the treatment of small P-NETs independently from their functional status.

\section{Introduction}

Pancreatic neuroendocrine tumors (P-NETs) are uncommon, although in recent years, an increased incidence has been reported [1]. While functional P-NETs (i.e. insulinomas, glucagonomas, vipomas, somatostatinomas) produce metabolic disorders and, therefore, are diagnosed early when still small [2], diagnosis of non-functional P-NETs is often delayed because symptoms only occur due to large tumor volume. For this rea- son, the former are usually treated with surgery and the latter are largely judged as unfit for surgery.

In recent years, enhanced imaging techniques such as endoscopic ultrasound (EUS) have resulted in earlier diagnosis of PNETs [2]. Once they are discovered, therapeutic decision-making remains quite complicated because surgery for small, nonfunctional P-NETs may be considered "overtreatment" burdened by high risk in a tumor with a relatively benign natural history [3]. 
Recently, EUS-guided radiofrequency ablation (RFA) has been described as a new therapeutic approach with significant effectiveness and safety when used for treating P-NETs. Currently, pancreatic EUS-RFA can be performed by using two different devices: the STARmed (Taewoong Medical, Gyeonggido, South Korea), an 19G RFA needle connected to a specific RF monopolar VIVA RFgenerator associated with a pump cooling the needle internally with chilled saline solution; and the Habib EUS RFA (EMcision Ltd, London, UK) device, which is a 1 $\mathrm{Fr}$ wire monopolar electrode that can be inserted inside a standard 22 G EUS fine-needle aspiration (FNA) needle, connected to a regular electrosurgical generator (ERBE Medizin VIO 200 or 300 series), and has no cooling system.

To date, only a few case reports and small case series (1-12 patients) have described the feasibility, effectiveness and safety of EUS-guided RFA treatment of P-NET [4-14]. We report 11 cases of P-NET managed in a single tertiary center, with the aim of exploring the effectiveness and safety of EUS-RFA in treatment of P-NET.

\section{Patients and methods}

\section{Study population}

The patients described here were treated consecutively in the Department of Gastroenterology and Digestive Endoscopy, Salvini Hospital, Garbagnate Milanese, Milan, Italy, between June 2016 and October 2018 and were followed up for at least 12 months. All patients included had histologically proven P-NET, $\leq 2 \mathrm{~cm}$ in size, and either were judged to be inoperable or refused surgery. Indications for endoscopic or surgical management were discussed in a multidisciplinary setting (gastroenterologists, surgeons, oncologists and pathologists). EUS was performed with a linear array echoendoscope (Pentax EG3870UTK; Pentax, Tokyo, Japan), while tissue acquisition was done through the gastric or duodenal wall depending on the tumor location, with the 19-gauge (G) flex (Expectflex, Boston Scientific Corp., Marlborough, Massachusetts, United States) for core and immunohistochemistry staining. All the subjects underwent total-body contrast-enhanced computed tomography (CT) and Gallium 68-based positron emission tomography $\left({ }^{68} \mathrm{GA} \mathrm{PET}\right)$ to detect pathological nodes or distant metastases.

As for the endoscopic RFA technique, all procedures were performed within 3 weeks after EUS/CT/ $/{ }^{68} \mathrm{GA}$ PET evaluation by using a linear-array therapeutic echoendoscope under deep sedation. Indomethacin (100-mg suppository) was administered prior to RFA for acute pancreatitis prophylaxis.

The EUS-RFA device consisted of a 19-gauge needle electrode with an active 5 - or 10 -mm tip and an internal cooling system (EUSRA system Taewoong, Combo VIVA ${ }^{\mathrm{TM}}$ generator STARmed). Under EUS guidance, a monopolar electrode needle with high-frequency alternating current was inserted into the target lesion while avoiding the pancreatic and bile ducts or maintaining a distance of at least $2 \mathrm{~mm}$ fron them to avoid damage or duct strictures. Injury to blood vessels was avoided with the help of Doppler evaluation.
The needle tip was positioned at the far end of the lesion. Energy was delivered when the needle tip of the electrode was visualized within the margin of the lesion on EUS and was stopped when impedance quickly increased, reaching at least 500 to 600 Ohms, as per the manufacturer's protocol.

Using 20 Watt for 10 to $25 \mathrm{sec}$, a 5 - or 10 -mm exposed active tip (according to the size of the tumor) produced an ablation area of about 10 to $25 \mathrm{~mm}$ after each application, recognized as a slowly increasing hyperechoic zone within the tumor. If needed, the electrode was repositioned under EUS guidance to ablate another area along the same trajectory.

The completeness of the treatment was assessed endosonographically with the administration of contrast medium Sonovue (Bracco, Milan, Italy) to evaluate for residual tissue to ablate, about 20 minutes after the RFA treatment. In case of active residual tissue, another treatment was performed during the same session.

After the procedure, all patients were fasted for at least 12 hours; analgesic (paracetamole $1 \mathrm{~g}$ ev bis in die) and antibiotic therapy (cephalosporin or fluoroquinolone) were administered; massive intravenous hydration $(30-40 \mathrm{ml} / \mathrm{kg} /$ die considering the comorbidities) and blood exam control 6-24-48 hours after RFA were performed. Finally, abdominal CT scans to control the complete ablation were performed 1 month, 6 and 12 months after procedure. Positive response was defined by absence of enhancing tissue at the tumor site on 6 -and 12month CT scans.

For patients with functioning insulinomas, endocrinological clinical controls every 4 weeks for the first 3 months and every 8 weeks for the following 9 months were prescribed.

Adverse events (AEs) were recorded in accordance with the following classification [9]: mild AEs: abdominal pain, mild increase of amylases ( $<3$ days hospital stay post-endoscopy), self-limiting fever; moderate AEs: acute pancreatitis, late onset of hematoma and ulceration in duodenal wall (medical control, no surgical intervention required); severe AEs: pancreatic necrotic lesion requiring surgical intervention by laparoscopy or endoscopic intervention (e.g. endoscopic drainage of intra-abdominal post-procedure collections).

\section{Statistical analysis}

Data were analyzed using the Statistical Package for Social Sciences (SPSS software v.15.0, Chicago Illinois, United States) for Windows. The descriptive statistics used included determination of mean values and standard deviation (SD) of the continuous variables, and of percentages and proportions of the categorical variables.

\section{Results}

\section{Patients}

We prospectively enrolled 10 patients ( 5 males, mean age 78.6 years, mean BMI 28.2) who had a total of 11 P-NETs with a mean size of $14.5 \mathrm{~mm}$ (range $9-20 \mathrm{~mm}$ ) localized in the pancreatic head (3 lesions), pancreatic body (5 lesions), and tail (3 lesions), respectively. The details of enrolled patients are reported in $>$ Table 1. 
- Table 1 Baseline characteristics and outcomes of the 10 patients who underwent radiofrequency ablation (RFA) of a pancreatic neuroendocrine tumor.

\begin{tabular}{|c|c|c|c|c|c|c|c|c|c|c|c|}
\hline $\begin{array}{l}\text { Patient } \\
\text { number }\end{array}$ & $\begin{array}{l}\text { Age } \\
\text { (Years) }\end{array}$ & Sex & $\begin{array}{l}\text { Clinical } \\
\text { presen- } \\
\text { tation }\end{array}$ & $\begin{array}{l}\text { Diag- } \\
\text { nosis }\end{array}$ & $\begin{array}{l}\text { Loca- } \\
\text { tion }\end{array}$ & $\begin{array}{l}\text { Size } \\
\text { of tu- } \\
\text { mor, } \\
\text { mm }\end{array}$ & $\begin{array}{l}\text { Electrode } \\
\text { caliber, G }\end{array}$ & $\begin{array}{l}\text { Re- } \\
\text { sponse }\end{array}$ & $\begin{array}{l}\text { Ses- } \\
\text { sions, } \\
\text { n }\end{array}$ & $\begin{array}{l}\text { Treatment } \\
\text { applications } \\
\text { per session, } \\
\mathbf{n}\end{array}$ & $\begin{array}{l}\text { Adverse } \\
\text { events }\end{array}$ \\
\hline 1 & 71 & $M$ & None & $\begin{array}{l}\text { Net G1 } \\
\text { ki67 <4 }\end{array}$ & Head & 20 & $\begin{array}{l}19 \mathrm{G} \\
10 \mathrm{~mm}\end{array}$ & Yes & 1 & 2 & $\begin{array}{l}\text { Mild ab- } \\
\text { dominal } \\
\text { pain }\end{array}$ \\
\hline 2 & 76 & $\mathrm{~F}$ & None & $\begin{array}{l}\text { Net G1 } \\
\text { ki67 }<1\end{array}$ & Body & 17 & $\begin{array}{l}19 \mathrm{G} \\
10 \mathrm{~mm}\end{array}$ & Yes & 1 & 3 & 0 \\
\hline 3 & 72 & $\mathrm{M}$ & $\begin{array}{l}\text { Hypogly- } \\
\text { caemia }\end{array}$ & $\begin{array}{l}\text { Net G1 } \\
\text { ki67 }<1\end{array}$ & Tail & 9 & $\begin{array}{l}19 \mathrm{G} \\
5 \mathrm{~mm}\end{array}$ & Yes & 1 & 2 & 0 \\
\hline 4 & 81 & $M$ & $\begin{array}{l}\text { Hypogly- } \\
\text { caemia }\end{array}$ & $\begin{array}{l}\text { Net G1 } \\
\text { ki67 }<1\end{array}$ & Body & 11 & $\begin{array}{l}19 \mathrm{G} \\
10 \mathrm{~mm}\end{array}$ & Yes & 1 & 3 & 0 \\
\hline 5 & 78 & $\mathrm{M}$ & None & $\begin{array}{l}\text { Net G1 } \\
\text { ki67<4 }\end{array}$ & Head & 12 & $\begin{array}{l}19 \mathrm{G} \\
10 \mathrm{~mm}\end{array}$ & Yes & 1 & 2 & $\begin{array}{l}\text { Mild ab- } \\
\text { dominal } \\
\text { pain }\end{array}$ \\
\hline 6 & 84 & $\mathrm{~F}$ & None & $\begin{array}{l}\text { Net G1 } \\
\text { ki67<4 }\end{array}$ & Tail & 20 & $\begin{array}{l}19 \mathrm{G} \\
10 \mathrm{~mm}\end{array}$ & Yes & 1 & 3 & 0 \\
\hline 7 & 86 & $\mathrm{~F}$ & $\begin{array}{l}\text { Hypogly- } \\
\text { caemia }\end{array}$ & $\begin{array}{l}\text { Net G1 } \\
\text { ki67 }<1\end{array}$ & Tail & 15 & $\begin{array}{l}19 \mathrm{G} \\
10 \mathrm{~mm}\end{array}$ & Yes & 1 & 2 & 0 \\
\hline 8 & 80 & $\mathrm{~F}$ & $\begin{array}{l}\text { Hypogly- } \\
\text { caemia }\end{array}$ & $\begin{array}{l}\text { Net G1 } \\
\text { ki67 }<1\end{array}$ & Body & 16 & $\begin{array}{l}19 \mathrm{G} \\
10 \mathrm{~mm}\end{array}$ & Yes & 1 & 2 & 0 \\
\hline 9 & 77 & $M$ & None & $\begin{array}{l}\text { Net G1 } \\
\text { ki67 }<1\end{array}$ & $\begin{array}{l}\text { Head + } \\
\text { Body }\end{array}$ & 15,12 & $\begin{array}{l}19 \mathrm{G} \\
10 \mathrm{~mm}\end{array}$ & Yes & 1 & 2 & 0 \\
\hline 10 & 81 & $\mathrm{~F}$ & $\begin{array}{l}\text { Hypogly- } \\
\text { caemia }\end{array}$ & $\begin{array}{l}\text { Net G1 } \\
\text { ki67 <1 }\end{array}$ & Body & 13 & $\begin{array}{l}19 \mathrm{G} \\
10 \mathrm{~mm}\end{array}$ & Yes & 1 & 2 & 0 \\
\hline
\end{tabular}

$\mathrm{N}$, number; NET, neuroendocrine tumor; RFA, radiofrequency ablation, M, male; F, female; G, gauge.

Five patients had symptomatic insulinomas (hypoglycemia with elevated fasting insulin and C-peptide levels was documented before EUS-RFA); 3 subjects had non functional intermediate P-NET (Ki $67<4 \%$ ) and 2 patients had low-grade PNET (Ki $67<1 \%$ ). None pathological nodes/distance metastases were detected with total body CT scan and ${ }^{68} \mathrm{GA}$ PET.

Seven patients were judged unfit for surgery for severe comorbidities (2 patients with severe cardiomyopathy and vascular illness and 2 with severe obesity) or advanced age (3 subjects), while the remaining three refused surgery.

\section{Effectiveness}

The procedure was technically successful (ability to target the RFA needle) in all patients and tumors. Complete ablation of PNET was achieved using a single-session RFA with a mean of 2.3 treatment applications per session ( $\mathbf{F i g . 1}$ ). In patients with insulinomas, hypoglycemia relief was almost immediate, with normalization of blood sugar levels within 24 hours. These patients remained euglycemic and asymptomatic at all visits through 12 months after insulinoma ablation.

At 6-month CT scan, all patients had complete disappearance of the lesions with radiological normalization. These findings were also confirmed at 12-month CT scan.

\section{Safety}

All RFA sessions ended with no early or late complications related to the procedure and no cases of bleeding were recorded. Only two cases of mild abdominal pain were recorded in two subjects with pancreatic head lesions, which were effectively treated with analgesics ( $\triangleright$ Table 1 ) (slight hyperamylasemia $<3 \times \leq 3 \times$ upper limited of normal - without abdominal pain was also observed in 3 subjects). The mean duration of hospital stay was 4 days (range $3-7$ days).

\section{Discussion}

Thanks to enhanced use of imaging techniques, the incidence of pancreatic neuroendocrine tumors has increased in recent years $[15,16]$, significantly increasing diagnosis of small, asymptomatic P-NETs [17].

To date, surgery is considered the only effective treatment for P-NET, and while it dramatically increases survival, it is burdened by a poor safety profile, both in the short and long term [18]. About this topic, Jilesen et al [19] in their systematic review of 62 studies, reported significant AEs after pancreatic surgery, which included pancreatic fistula (up to $58 \%$ ), delayed 

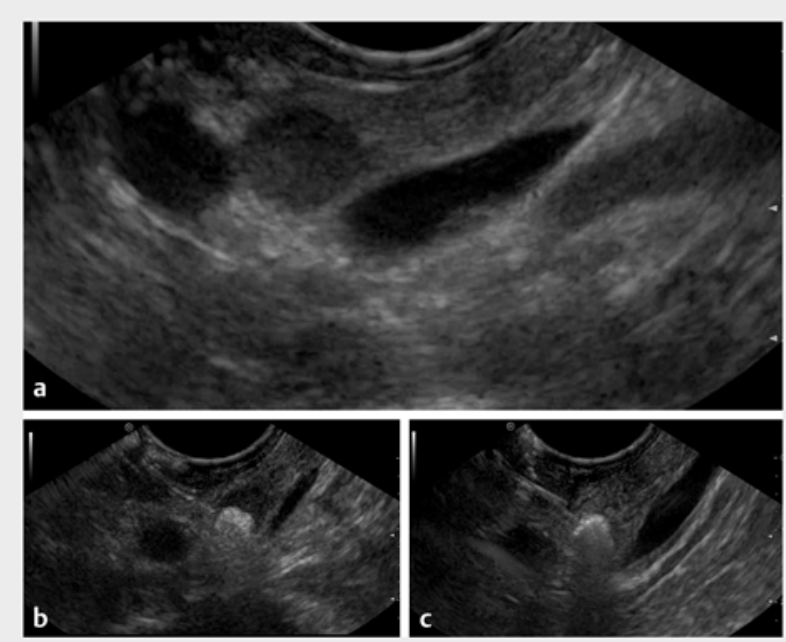

- Fig. 1 Endoscopic ultrasound-guided radiofrequency ablation (EUS-RFA) for pancreatic neuroendocrine tumors (P-NETs). a EUS views showing a NET located in the body of the pancreas. b,c RFA with visible white bubbles within the NET.

gastric emptying (up to $18 \%$ ) and postoperative bleeding (up to $6 \%$, and an overall in-hospital mortality of $6 \%$. Furthermore, longer hospital stays have been described with both laparoscopic and open pancreatic surgery [20].

On the basis of these well-known limitations of surgery in treating pancreatic neoplasms, non-surgical, safer, effective, and less invasive therapies are warranted [21].

EUS-RFA recently has been described as a new, non-surgical, effective, and safe therapeutic option for patients with P-NETs [4-14].

In the present study, we reported 11 cases of P-NETs prospectively followed up for 12 months and demonstrated complete ablation using a single-session RFA procedure without severe early or late complications.

About effectiveness, at 6-month CT scan, all patients had complete disappearance of lesions with radiological normalization. These outcomes were also confirmed at 12-month CT scan. These results are similar to those of Barthet et al [13], which showed complete disappearance or necrosis of the lesion in $92.3 \%$ of P-NETs at 1 -year follow-up evaluation. It is important to emphasize that in functional P-NETs (mostly insulinomas), given their very low malignancy, there is theoretically no need to achieve complete ablation, except when reducing the cell mass is required to decrease insulin production [20].

About safety, only two cases of mild abdominal pain, responsive to analgesic, occurred. Furthermore, slight hyperamylasemia $-<3 \times \leq 3 \times$ the upper limit of normal - without abdominal pain was also observed in three subjects. The mean duration of hospital stay was 4 days. In patients with insulinomas, hypoglycemia relief was quick, and they remained euglycemic and asymptomatic at the 12-month follow up. Our results are similar to those reported by Barthet et al [13], and better than those of Choi et al [10], probably due to the more stringent inclusion criteria we used. Furthermore, we administered non- steroidal anti-inflammatory drugs to all our patients in suppositories to prevent acute pancreatitis, although this treatment is not standard. In previous case reports, only one case of necrotizing pancreatitis was recorded [13], while others reported only a few mild AEs, confirming our results.

On the basis of our data, selection of patients for EUS-RFA remains challenging, because it should be based on patient profile (comorbidities, surgical risk, life expectancy), tumor features (location and mass size) and endoscopist experience.

Our study presents some limitations, which deserve a discussion. First, presumptive tumor eradication has been based only on imaging of P-NETs while histology is lacking; this limitation is, however, shared by all studies available in the literature and included in our analysis, a fact that makes imaging-based follow-up the current standard of care for management of PNETs with EUS-RFA. Second, the follow-up period in our series was no longer than 12 months, but that is comparable to previous studies about this topic. EUS-RFA is a novel technique and long-term data on it thus are lacking. Larger studies with longer follow-up are needed to evaluate the long-term effectiveness of EUS-RFA. Finally, the setting for the radiofrequency generator has not been standardized. We decided to use 20 Watts to treat the lesions, a value that differs from that used in other studies (10-50 Watts) $[9,10,13]$, but which slowly cooks the lesion, likely optimizing effectiveness, controlling extension of the treated area, and minimizing risk of pancreatic tissue damage and $\mathrm{AE}$.

\section{Conclusion}

In conclusion, EUS-RFA represents an effective and safe treatment for management of P-NETs and can be considered as a therapeutic option for small P-NETs. Larger series with longer follow-up are needed to better define which patients with $\mathrm{P}$ NETs would benefit from endoscopic therapy and which would be better treated surgically.

\section{Competing interests}

The authors declare that they have no conflict of interest.

\section{References}

[1] Fitzgerald TL, Hickner Z], Schmitz $M$ et al. Changing incidence of pancreatic neoplasms: a 16-year review of statewide tumor registry. Pancreas 2008; 37: 134-138

[2] Lee DW, Kim MK, Kim HC. Diagnosis of pancreatic neuroendocrine tumors. Clin Endosc 2017; 50: 537-545

[3] Sachs T, Pratt WB, Callery MP et al. The incidental asymptomatic pancreatic lesion: nuisance or treat? J Gastrointest Surg 2009; 13 405-415

[4] Rossi S, Viera FT, Ghittoni G et al. Radiofrequency ablation of pancreatic neuroendocrine tumors: a pilot study of feasibility, efficacy, and safety. Pancreas 2014; 43: 938-945 
[5] Armellini E, Crinò SF, Ballarè M et al. Endoscopic ultrasound-guided radiofrequency ablation of a pancreatic neuroendocrine tumor. Endoscopy 2015: (Suppl. 01): 47

[6] Pai M, Habib N, Senturk H et al. Endoscopic ultrasound guided radiofrequency ablation, for pancreatic cystic neoplasms and neuroendocrine tumors. World J Gastrointest Surg 2015; 7: 52-59

[7] Lakhtakia S, Ramchandani M, Galasso D et al. EUS-guided radiofrequency ablation for management of pancreatic insulinoma by using a novel needle electrode (with videos). Gastrointest Endosc 2016; 83: 234-239

[8] Waung JA, Todd JF, Keane MG et al. Successful management of a sporadic pancreatic insulinoma by endoscopic ultrasound-guided radiofrequency ablation. Endoscopy 2016; 48: (Suppl. 01): E144E145

[9] Bas-Cutrina F, Bargalló D, Gornals JB. Small pancreatic insulinoma: Successful endoscopic ultrasound-guided radiofrequency ablation in a single session using a 22-G fine needle. Dig Endosc 2017; 29: 636638

[10] Choi JH, Seo DW, Song TJ et al. Endoscopic ultrasound-guided radiofrequency ablation for management of benign solid pancreatic tumors. Endoscopy 2018; 50: 1099-1104

[11] Thosani N, Sharma NR, Raijman I et al. 483 Safety and efficacy of endoscopic ultrasound guided radiofrequency ablation (EUS-RFA) in the treatment of pancreatic lesions: a multi-center experience. Gastrointest Endosc 2018; 87: AB84

[12] Gueneau de Mussy P, Lamine F, Godat S et al. A case of benign insulinoma successfully treated with endoscopic ultrasound guided radiofrequency ablation. Endocrine Abstr 2018; 56: 121

[13] Barthet M, Giovannini M, Lesavre N et al. Endoscopic ultrasoundguided radiofrequency ablation for pancreatic neuroendocrine tu- mors and pancreatic cystic neoplasms: a prospective multicenter study. Endoscopy 2019; 51: 836-842

[14] Oleinikov K, Dancour A, Epshtein J et al. Endoscopic ultrasound guided radiofrequency ablation: a new therapeutic approach for pancreatic neuroendocrine tumors. J Clin Endocrinol Metab 2019; 104: 2637-2647

[15] Yao JC, Hassan M, Phan A et al. One hundred years after "carcinoid": epidemiology of and prognostic factors for neuroendocrine tumors in 35,825 cases in the United States. J Clin Oncol 2008; 26: 3063-3072

[16] Halfdanarson TR, Rubin J, Farnell MB et al. Pancreatic endocrine neoplasms: epidemiology and prognosis of pancreatic endocrine tumors. Endocr Relat Cancer 2008; 15: 409-427

[17] Hallet J, Law $\mathrm{CH}$, Cukier $\mathrm{M}$ et al. Exploring the rising incidence of neuroendocrine tumors: a population-based analysis of epidemiology, metastatic presentation, and outcomes. Cancer 2015; 121: 589-597

[18] Hill JS, McPhee JT, McDade TP et al. Pancreatic neuroendocrine tumors: the impact of surgical resection on survival. Cancer 2009; 115: 741-751

[19] Jilesen AP, van Eijck CH, in't Hof KH et al. Postoperative complications, in-hospital mortality and 5-year survival after surgical resection for patients with a pancreatic neuroendocrine tumor: a systematic review. World J Surg 2016; 40: 729-748

[20] Belfiori G, Wiese D, Partelli S et al. Minimally invasive versus open treatment for benign sporadic insulinoma comparison of short-term and long-term outcomes. World J Surg 2018; 42: 3223-3230

[21] Larghi A, Rizzatti G, Rimbaş M et al. EUS-guided radiofrequency ablation as an alternative to surgery for pancreatic neuroendocrine neoplasms: Who should we treat? Endosc Ultrasound 2019; 8: 220-226 